ings. The co-ordination of all research work connected with the applications of electricity to agricultural and horticultural work is now almost complete: plans have been prepared during the year for the establishment of a field station associated with the University of Reading, and a working liaison has been established with the Scottish Hydro-Electric Board.

Special attention has been giyen to research required for the further commercial development of gas-blast circuit brealkers. The electric control apparatus section has prepared a further important series of reports for dealing with industrial explosion hazards. The importance of work on the creep of steels has been recognized by expansion of the scale of working at the National Physical Laboratory, and some success has been achieved in applying similar ideas in the study of insulating materials subjected. to continued high mechanical stresses at working temperatures, a subject representing practically an unworked field until tackled by the Association.

Continuous attention has been given to the examination of new insulating materials and to the research necessary for their standardization, and generally to improvements in methods of selection and testing. The practical value of applying modern statistical and other scientific methods in the study of electricity supply technology is receiving increasing recognition, and when the War ends will, no doubt, be pursued on a more adequate scale. Several notable reports have been issued during the year applying to surge phenomena, transformer design and meter jewels. Work on interference with communication circuits which applied mainly to particular war products has led indirectly to an important new development affording a scientific basis for the design of ignition systems adapted to all types of engines and to varied working conditions.

\section{CERAMIC SEQUENCES AT TRES ZAPOTES, MEXICO}

$\mathrm{T}$ HE second season's work of the National Geographic-Smithsonian Institution joint archæological expedition to southern Veracruz in 1940 has now been described in Bull. 140 of the Bureau of American Ethnology*. Bull. 139, giving an account of the 1939 season's work by G. W. Weiant, has already been noticed in Nature (July 22, 1944, p. 124). The aim of the 1940 work, by Philip Drucker, was to follow up the preliminary exploration of 1939 with careful stratigraphical excavations, upon which a ceramic sequence could be based. The results indicate two considerable alterations in Weiant's succession. The evidence is not absolutely conclusive on every point, but it is sufficient to confirm the suggestion made in the previous notice that his publication was premature.

The chief result of the 1940 work was to mark the essential unity and continuity of the Lower, Middle and Upper Tres Zapotes 'periods', which are renamed 'phases' to emphasize the point, and to separate Weiant's Upper period into a true Upper Tres Zapotes phase and an unconformable "Soncautla Complex", consisting of cremated burials (the "cremated burials in covered bowls" of the previous notice) intruded into deposits of the Upper phase. The Tres Zapotes

* Smithsonian Institution: Bureau of American Ethnology. Bull. 140: Ceramic Sequences at Tres Zapotes, Veracruz, Mexico. By Philip Drucker. Pp. ix $+155+65$ plates.
ment Printing Office, 1944.) 50 cents. period, sensu stricto, is shown to cover an occupation of long duration, after which the site was abandoned, and later used for the Soncautla burials for a short time. So far, the piature is entirely convincing ; but Drucker also points out that he cannot confirm Weiant's division of the Middle period into $A$ and $B$ stages, admitting at the same time that this may be due to the absence of $A$ deposits from the places excavated by him.

Much of the material found in the 1940 work consists of sherds, and this has imposed a simpler system of classification than Weiant's, in which a relatively small number of wares are based on characteristics of slip, vessel shape and paste. The distinguishing features of the Lower, Middle and Upper Tres Zapotes phases are clearly pointed out in terms of these wares. The figurines are divided into three main types; the first to appear, which persisted throughout, are hand-made and mostly solid, whereas the other two are found in the Upper phase only, one being hollow moulded and the other large and elaborately modelled by hand, with jointed limbs.

A tentative chronology of the site is sketched out, and in this connexion there are two strong indications of an early date in the complete lack of metal and of Plumbate and Fine Orange wares. The Lower Tres Zapotes phase is shown to be linked with the early Lowland Maya, to the exclusion of the early Highland cultures such as those of Monte Alban and the Valley of Mexico. It is suggested that it was in existence in the first century B.C. The Middle phase is essentially one of transition, but the Upper is marked by a large increase of Polychrome sherds, and the introduction of some new elements which, it is conjectured, may have diffused from Teotihuacan. The date of the close of the Tres Zapotes occupation is estimated in round figures as A.D. 1000. This was followed by a period long enough for the accumulation of a certain amount of humus, after which came the Soncautla burials, which are very tentatively ascribed to the thirteenth century.

This bulletin shows a very considerable improvement on No. 139 in the provision of scales on illustrations and plans. Three misprints in references to plates were noticed: plate 18 at the top of p. 41 should be 16 , Plate 10 at the bottom of p. 43 should be 14, and plate 56 on line 9 of p. 84 should be 59 .

\section{G. H. S. Bushnell.}

\section{FORTHCOMING EVENTS}

Saturday, March 17

Biochemical Societx (at the Middlesex Hospital Medical School, London, W.1), at 2 p.m.-Annual General Meeting.

institution of Mechanical ENGineERs (Graduates' SECtion) (at Storey's Gate, St. James's Park, London, S.W.1) at 3.30 p.m.-
Mr. A. H. Lloyd: "British Machine Tools during the War" (Annual Mr. A. H.

Royat Photographic Societr (Sclentifio and TeChNical Group) (at 16 Prince's Gate, South Kensington, London, S.W.7).-Mr. L: V. Chilton : First Renwick Memorial Lecture.

\section{Tuesday, March 20}

ROYAL SOCIETY OF ARTS (DOMINIONS AND COLONIES SECTION) (at John Adam Street, Adelphi, London, W.C.2), at 1.45 p.m.-Dr. A. C. Thaysen: "Food Yeast, its Nutritive Value and its Production from Empire Sources".

Chemical Enainekring Grodp (Soctety of Chemical Indostry) (joint meeting with the INSTITUTION OF CHEMICAL ENGINEERS) (at the Geological Society, Buríngton House, Piccadilly, London, W.j), at 2.30 p.m.-Discussion on "Industrial Research"' (to be opened' by Dr. E. W. Smith)

ROYAL INSTI UTION (at 21 Albemarle Street, London, W.1), at 5.15 p.m.- Sir Henry Dale, O.M., Pres.R.S. : "Nerve Endings and Motor Nerve Endings and Electric Organs". 